\title{
NEW MARKERS OF HUMAN CUMULUS OOPHORUS CELLS CULTURED IN VITRO - TRANSCRIPTOMIC PROFILE
}

\author{
Maciej Brązert ${ }^{1}$, Wiesława Kranc ${ }^{2}$, Karol Jopek ${ }^{3}$, Bartosz Kempisty ${ }^{2,3,4,5}$, Leszek Pawelczyk ${ }^{1}$
}

\begin{abstract}
The presence of CCs around the oocyte after ovulation is one of the key elements contributing to oocyte developmental competence. In the presented study, we used CCs from 12 patients aged 18-40 diagnosed with infertility. After harvesting cells on day 1, 7,15 and 30 of culture, total RNA was isolated and transcriptomic analysis was performed. The DAVID software indicated the following GO BP terms: "cell junction organization", "cell migration", "cell morphogenesis involved in differentiation", "cell morphogenesis" and "cell motility". Of the genes belonging to all ontological groups, the most downregulated were: SLC7A8, DFNB31, COL1A1, CDC42SE1, TGFBR3, HMGB1, with the most upregulated genes being: ANXA3, KIAA1199, HTR2B, VCAM1, DKK1.

While many studies focus on attempts to obtain fully competent oocytes, scientists still have difficulty attaining adequate results in vitro. Lack of adequate knowledge often results in low in vitro fertilization efficiency. Therefore, our research focuses on CCs cells, thanks to which the oocyte most likely acquires developmental competence. The main purpose of the study was to identify the potential molecular markers responsible for cell junction organization, migration, differentiation, morphogenesis and motility.
\end{abstract}

Running title: New markers of human cumulus oophorus cells cultured in vitro

Keywords: cumulus ophorus cells, microarrays, human reproduction

\footnotetext{
${ }^{1}$ Division of Infertility and Reproductive Endocrinology, Department of Gynecology, Obstetrics and Gynecological Oncology, Poznań University of Medical Sciences, 33 Polna St., 60-535 Poznań, Poland

${ }^{2}$ Department of Anatomy, Poznań University of Medical Sciences, 6 Święcickiego St., 60-781 Poznań, Poland

${ }^{3}$ Department of Histology and Embryology, Poznań University of Medical Sciences, 6 Świecickiego St., 60-781 Poznań, Poland

${ }^{4}$ Department of Obstetrics and Gynecology, University Hospital and Masaryk University, 20 Jihlavská St., 62500 Brno, Czech Republic

${ }^{5}$ Department of Veterinary Surgery, Institute of Veterinary Medicine, Nicolaus Copernicus University in Toruń, 1 Lwowska St., 87-100 Toruń, Poland

* Correspondence: e-mail: bkempisty@ump.edu.pl

Full list of author information is available at the end of article
} 


\section{Introduction}

Cumulus cells (CCs) are differ significantly from granulosa cells (GCs), resting on the basal lamina of ovarian follicle. CCs are in close physical contact with the oocyte, forming a cumulus-oocyte complex (COC). The oocyte controls the differentiation and expansion of CCs, which in turn are involved in the metabolism of pyruvate and glucose consumed during energy production in the oocyte $[1,2]$. Due to this proximity, CCs are influenced by regulatory factors produced by the oocyte. These regulatory factors include primarily: growth differentiation factor 9 (GDF9), bone morphogenetic protein 15 (BMP15) and fibroblast growth factor 8 (FGF8). They are primarily responsible for suppressing expression of the LH receptor and genes responsible for steroid production. Unlike the GCs, which "remain" in the ruptured follicle, CCs are "ejected" from the ruptured follicle during ovulation [3]. CCs also produce many inflammatory factors and cytokines that are released during ovulation. Cumulus cell-oocyte complex (COC) released from the ovary is therefore a kind of a microenvironment [4-6]. Increased concentration of gonadotropins in the female body causes increased production of hyaluronic acid by CCs, which expands the spaces between these cells. Correct ovulation requires the production of prostaglandins. GDF9 (a member of the TGF-beta superfamily) plays a major role in the induction of Ptgs2 expression in CCs through increased luteinizing hormone (LH) concentration. Lack of GDF9 blocks the development and growth of follicles, thus leading to infertility [7].

In most mammal species, including humans, CCs cells surround the oocyte at conception. It is believed that CCs interact with the oocyte and sperm, and thus are involved in promoting the fertilization process and oocyte developmental competence $[8,9]$. It has been proven many years ago that CCs are involved in maintaining myocyte retention in the oocyte. Oocytes removed from the follicle, lacking CCs, resume meiotic division, which should be completed only after fertilization [10]. In addition, CCs facilitate the capture of COC by ciliated oviduct cells [11]. Glycodelin-C, a derivative of glycodelin, is isolated from the matrix of CCs cells. This substance stimulates the binding of spermatozoa to the zona pellucida of oocyte [9]. It has also been reported that the rate of CCs associated with morphologically abnormal oocytes or immature oocytes is much higher than in CCs surrounding morphologically normal, mature oocytes. The increase in CC apoptosis has a negative impact on a number of processes related to the correct fertilization and development of blastocyst and reduces the effectiveness of in vitro fertilization (IVF) [12,13].

The expression of genes associated with the proper function of CCs results from a number of factors produced by the oocyte, but also the environ- ment of the mature ovarian follicle, and all processes occurring during follicle growth in the ovarian microenvironment [14].

CCs also produce antioxidant compounds that reduce the level of oxidative stress caused by reactive oxygen species (ROS). These compounds, mainly superoxide dismutase (SOD) [15] and Glutathione transferase S theta 1 (GSTT1) protect the oocyte against oxidative stress [16,17].

Knowledge about the expression of individual genes, as well as the presence of individual components of the intracellular metabolic pathways, or the CCs apoptosis index can become a source of valuable molecular markers determining the developmental competence of oocytes. It is known that the expression of amphiregulin (AREG) and epiregulin (EREG) (epidermal growth factor (EGF) -like factors) depends on the dose of LH administered during ovarian stimulation. Therefore, it is suggested that AREG and EREG are part of the signal transduction pathway, which leads to the release of the oocyte from the mature ovarian follicle and the luteinization process in women [18]. Recent studies described of new properties of CCs. CCs produce a large amount of hyaluronan, which targets CD44 (marker of cancer cells). Culture of pancreatic cancer cells in a medium conditioned with CCs activated pro-apoptotic genes in these cancer cells [19]. The mechanisms of communication between the oocyte and CCs cells through gap connections are well known. It is known, however, that this communication also takes place by means of paracrine signaling. Less known methods of communication are the transfer of non-coding RNAs through exosomes from the cumulus to the oocyte [20]. Coenzyme Q10 (CoQ) is another factor that has a significant impact on the quality of oocyte and CCs cells. This relationship is important for the proper functioning of mitochondria, not only in the oocyte but also in CCs cells. A decrease in mitochondrial activity is associated with aging of oocytes. Therefore, reduced $\mathrm{CoQ}$ production in older women translates into reduced fertility and a higher risk of birth defects for embryos [21].

Understanding the molecular mechanisms and regulation of gene expression in CCs may reflect processes in the oocyte. Changes occurring at the molecular level may be a signpost for identifying oocyte quality, oocyte acquisition of developmental competences, and quality of obtained blastocyst. The main purpose of the research was to identify the potential molecular markers responsible for cell junction organization, migration, differentiation, morphogenesis and motility.

\section{Material \& Methods \\ Patients}

CCs were obtained from patients undergoing IVF. The study used CCs from 12 patients aged 1840 diagnosed with infertility. The factors excluding 
patients from these studies were: polycystic ovary syndrome (PCOS), AMH less than $0.7 \mathrm{ng} / \mathrm{ml}$, antral follicle count less than 9, day 2-3 FSH serum level higher than $15 \mathrm{mU} / \mathrm{ml}$ and endometriosis. All in vitro fertilization procedures were conducted in the Department of Infertility and Reproductive Endocrinology, Poznan Medical University, Poland.

The IVF procedure was based on adapted and controlled ovarian hyperstimulation protocol. FSH (Gonal-F, Merck Serono) and highly purified hMG-HP (Menopur, Ferring) were used for ovarian stimulation. Additionally, to stop pituitary functions, Cetrorelix Acetate (Cetrotide, Merck Serono) injections at the right dose were performed. Ovulation was induced by injection of $6500 \mathrm{U}$ hCG (Ovitrelle, Merck-Serono).

After oocyte pick-up (OPU), oocyte-cumulus complexes (COCs) have been selected by an embryologist for further IVF procedure. In the next step of IVF routine, the obtained COCs were denuded. Corona radiata cells and cumulus oophorus somatic cells forming COCs have been removed during denudation process (800 IU/mL of HYASE-10X). CCs obtained in this way from multiple follicles of one patient were pooled and transferred to cell culture laboratory for further analysis.

\section{Condition of long-term primary in vitro culture}

CCs were collected after denudation of oocytes. Afterwards, they were washed twice with basal culture medium and centrifuged at RT (200 x g for $10 \mathrm{~min}$ ). Basal culture medium consisted of DMEM (Dulbecco's Modified Eagle's Medium, Sigma; Merck KGaA, Darmstadt, Germany) supplemented with $10 \mathrm{mg} /$ $\mathrm{ml}$ gentamicin (Invitrogen; Thermo Fisher Scientific, Inc.), 2\% fetal bovine serum FBS (FBS; Sigma; Merck KGaA), 4 mM L-glutamine (stock 200 mM, Invitrogen; Thermo Fisher Scientific, Inc., Waltham, MA, USA), $10,000 \mathrm{U} / \mathrm{ml}$ penicillin and $10,000 \mu \mathrm{g} / \mathrm{ml}$ streptomycin (Invitrogen; Thermo Fisher Scientific, Inc.) [22].

CCs were cultured at $37^{\circ} \mathrm{C}$ in $5 \% \mathrm{CO}_{2}$ and humid atmosphere. After attaining 90\% confluence, the cells in the culture were detached from the bottom of the 6-well plate by 1-2 min incubation with $0.05 \%$ trypsin-EDTA (Invitrogen; Thermo Fisher Scientific, Inc.). Later, the cells were counted using the ADAM Cell Counter and Viability Analyzer (Bulldog Bio). CCs were cultured fir 30 days. Medium was changed every 72-75 hours of culture. Cells for the analysis were harvested on day 1, 7, 15 and 30 of in vitro culture.

\section{Total RNA isolation}

After harvesting cells on the $1^{\text {st }}, 7^{\text {th }}, 15^{\text {th }}$ and $30^{\text {th }}$ day of culture, total RNA was isolated. The process of RNA isolation was performed according to modified method of Chomczyński and Sacchi [23]. Briefly, obtained CCs were suspended in $1 \mathrm{ml}$ of monophasic guanidine thiocyanate and phenol solution (TRI Re- agent $\AA$, Sigma; Merck KGaA). Next, chloroform was added to separate the phases during centrifugation. The upper aqueous phase, containing isolated RNA, was collected. RNA was extracted with 2-propanol (Sigma; Merck KGaA, catalog number I9516), added in an amount adequate for $1 \mathrm{ml}$ of TRI-reagent. Finally, RNA was washed with $75 \%$ ethanol, dried, resuspended in $20 \mu \mathrm{l}$ of pure water and measured.

\section{Microarray expression analysis and statistics}

Total RNA (100ng) was converted to double-stranded cDNA. In the next step, labeled complementary RNA (cRNA) was synthesized and amplified by in vitro transcription of the double-stranded cDNA template (GeneChip ${ }^{\mathrm{TM}}$ 3'IVT PLUS Reagent Kit, Applied Biosystems ${ }^{\mathrm{TM}}$, Foster City, CA, USA). Obtained cRNA was fragmentated by divalent cations and elevated temperature. Fragmentated and labeled cRNA $(7.5 \mu \mathrm{g})$ were hybridized to Human Genome U219 Array Strip $\left(45^{\circ} \mathrm{C} / 16 \mathrm{~h}\right.$, Applied Biosystems $^{\mathrm{TM}}$, Foster City, CA, USA). Then, the microarrays were washed and stained according to the technical protocol using Affymetrix GeneAtlas Fluidics Station. Subsequently, the array strips were scanned by Imaging Station of the GeneAtlas System. The preliminary analysis of the scanned chips was performed using Affymetrix GeneAtlas ${ }^{\mathrm{TM}}$ Operating Software. The quality of gene expression data was checked according to quality control criteria provided by the software. Obtained CEL files were imported into downstream data analysis software. All of presented analyses and graphs were performed by Bioconductor and R programming language. Each CEL file was merged with a description file. In order to correct background, normalize and summarize results, we used the Robust Multiarray Averaging (RMA) algorithm.

Statistical significance of the analyzed genes was performed by moderated t-statistics from the empirical Bayes method. Obtained p-value was corrected for multiple comparisons using the Benjamini and Hochberg's false discovery rate. The selection of significantly changed gene expression was based on p-value beneath 0.05 and expression fold higher than 2 . Differentially expressed genes were subjected to the selection of genes involved in cellular morphogenesis, junction and migration. Differentially expressed gene list was uploaded to the DAVID software (Database for Annotation, Visualization and Integrated Discovery), where "cell junction organization", "cell migration", "cell morphogenesis involved in differentiation", "cell morphogenesis" and "cell motility" GO BP terms were obtained. Expression data of these genes were subjected to hierarchical clustering procedure and presented as a heatmap graph. Detailed analysis of genes belonging to selected GO BP terms were presented as plots using "GOplot" library [24].

Moreover, the list of differentially expressed genes from selected GO BP terms was uploaded to the 

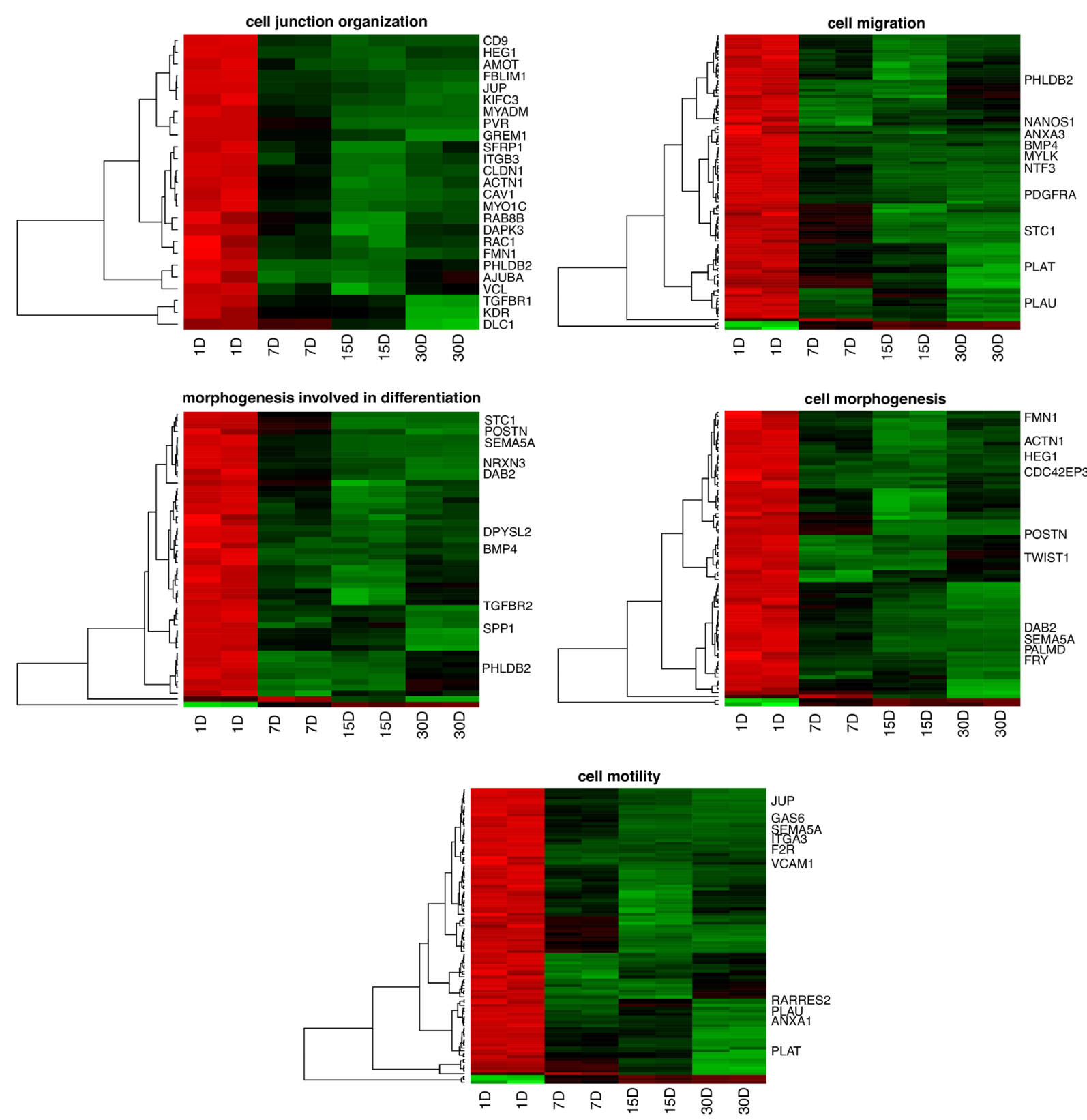

FIGURE 1 Heatmaps presenting differentially expressed genes involved in "cell junction organization", "cell migration", "cell morphogenesis involved in differentiation", "cell morphogenesis" and "cell motility" based on GO BP terms. Each row on the $\mathrm{Y}$ axis represents a single transcript. The red color indicates downregulated genes while the green are upregulated

STRING software (Search Tool for Retrieval of Interacting Genes/Proteins) for interaction prediction.

Finally, we used ReactomeFIViz app from the Cytoscape software for creating the Reactome Functional Interaction (FI) network from the set of differentially expressed genes.

\section{Ethical approval}

This research has been approved by Poznań University of Medical Sciences Bioethical Committee with 1290/18 resolution.

\section{Results}

We used Human Genome U219 Array Strip for the microarray gene expression analysis of human cumulus oophorus cells. This method allowed us to study the gene expression of 22,480 transcripts at $1,7,15$ and 30 days of in vitro cumulus oophorus cell culture. We selected genes with more than 2 - fold changes and corrected p-values less than 0.05 for downstream analysis. A total of 4773 differentially expressed genes (DEGs) were identified according to the above criteria. We started the microarray gene expression analysis with subjecting the list of DEGs to DAVID software, which showed that the genes can be assigned to 775 GO BP, 33 GO MF and 125 GO CC gene ontology terms. This paper focused on the genes involved cellular morphogenesis, junction and migration. The DAVID software indicated the following GO BP terms, which cover the 
TABLE 1 The 10 most significantly upregulated and all of the downregulated genes involved cellular morphogenesis, junction and migration

\begin{tabular}{|c|c|c|c|}
\hline Gene symbol & Gene name & Fold change & Adj. p.val \\
\hline DKK1 & dickkopf WNT signaling pathway inhibitor 1 & 34.81 & $<0.05$ \\
\hline ANXA3 & annexin $A 3$ & 34.27 & $<0.05$ \\
\hline KIAA1199 & KIAA1199 & 27.73 & $<0.05$ \\
\hline VCAM1 & vascular cell adhesion molecule 1 & 26.69 & $<0.05$ \\
\hline HTR2B & 5-hydroxytryptamine (serotonin) receptor $2 \mathrm{~B}, \mathrm{G}$ protein-coupled & 24.33 & $<0.05$ \\
\hline CTGF & connective tissue growth factor & 18.97 & $<0.05$ \\
\hline TGFBR2 & transforming growth factor, beta receptor II (70/80kDa) & 15.71 & $<0.05$ \\
\hline STC1 & stanniocalcin 1 & 14.96 & $<0.05$ \\
\hline $\mathrm{CD} 74$ & CD74 molecule, major histocompatibility complex, class II invariant chain & 14.18 & $<0.05$ \\
\hline SEMA5A & sema domain, seven thrombospondin repeats (type 1 and type 1-like), transmembrane domain (TM) and short cytoplasmic domain, (semaphorin) 5A & 13.15 & $<0.05$ \\
\hline SLC7A8 & solute carrier family 7 (amino acid transporter light chain, L system), member 8 & -2.00 & $<0.05$ \\
\hline DFNB31 & deafness, autosomal recessive 31 & -2.01 & $<0.05$ \\
\hline COL1A1 & collagen, type I, alpha 1 & -2.03 & $<0.05$ \\
\hline CDC42SE1 & CDC42 small effector 1 & -2.04 & $<0.05$ \\
\hline TGFBR3 & transforming growth factor, beta receptor III & -2.05 & $<0.05$ \\
\hline HMGB1 & high mobility group box 1 & -2.05 & $<0.05$ \\
\hline
\end{tabular}

7D/1D

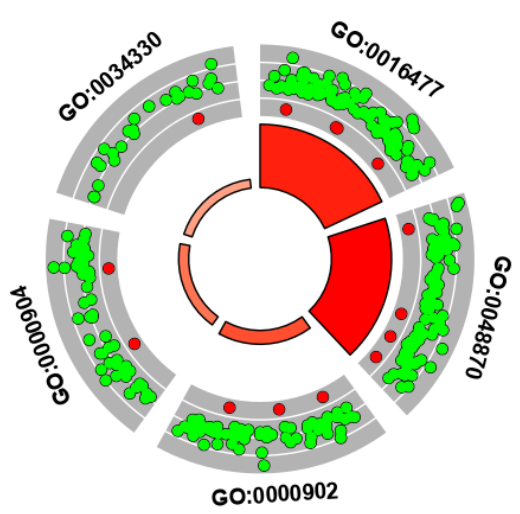

15D/1D

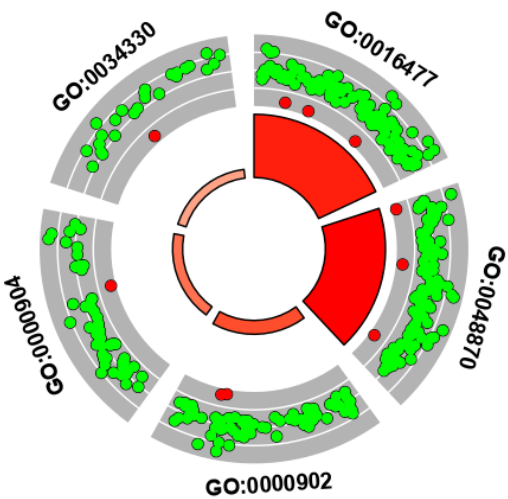

30D/1D

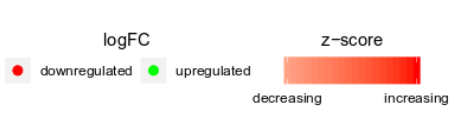

\begin{tabular}{|c|c|}
\hline ID & Description \\
\hline GO:0016477 & cell migration \\
\hline GO:0048870 & cell motility \\
\hline GO:0000902 & cell morphogenesis \\
\hline GO:0000904 & cell morphogenesis involved in differentiation \\
\hline GO:0034330 & cell junction organization \\
\hline
\end{tabular}

FIGURE 2 The circular scatter plots of differentially expressed genes involved in "cell junction organization", "cell migration", "cell morphogenesis involved in differentiation", "cell morphogenesis" and "cell motility" GO BP terms. Each dot represents a single gene. The z-scores were presented as segments of inner circles

above processes: "cell junction organization", "cell migration", "cell morphogenesis involved in differentiation", "cell morphogenesis" and "cell motility". The 150 genes involved in those processes were clustered using hierarchical clustering and presented as heatmaps (Fig. 1). It is worth mentioning that 144 genes were upregulated, which is the greater part of the list of genes used for hierarchical clustering. The downregulated genes are: $S L C 7 A 8$ - solute carrier family 7 (amino acid transporter light chain, L system), member 8; DFNB31- deafness, autosomal recessive 31; COL1A1- collagen, type I, alpha 1; CDC42SE1- CDC42 small effector 1; TGFBR3- transforming growth factor, beta receptor III; HMGB1- high mobility group box 1 . The direction of expression change (upregulation or downregulation) was maintained in cumulus oophorus cell culture in subsequent points of analy- sis (after 7, 15 and 30 days of in vitro culture). The 10 most significantly upregulated and all of the downregulated genes, their symbols, fold changes and corrected p- values are shown in table 1.

In the next part of analysis, we focused on the z-scores, which tell us whether the molecular function is more likely to be decreased (negative value) or increased (positive value). The z-scores were presented as segments of inner circles in the figure 2 . As can be seen from the figure, expression of most genes was increased (green dots) in all ontological groups. The z-scores of above-mentioned GO BP terms had positive values, so the processes described by these GO BP terms were upregulated. The expression pattern did not change at any of the analyzed time points. Considering the above, the subsequent analysis was based only on 7D/1D comparison. 

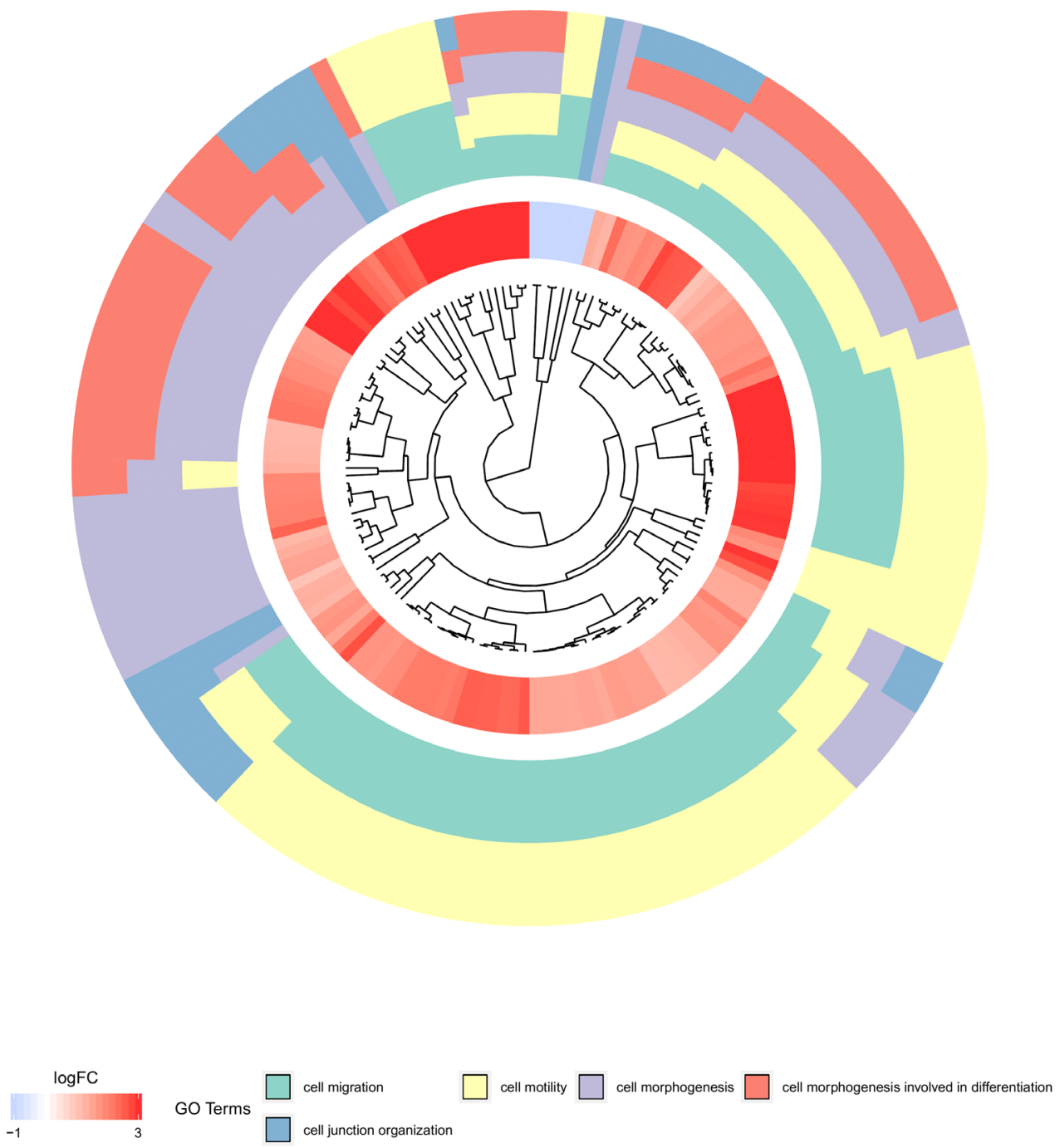

FIGURE 3 The dendrogram of differentially expressed genes involved in "cell junction organization", "cell migration", "cell morphogenesis involved in differentiation", "cell morphogenesis" and "cell motility" GO BP terms. The DEGs were clustered based on their $\log \mathrm{FC}$ values

In the next section, we checked the interaction between selected ontological groups. One of the most visually appealing way of presenting such interaction is dendrogram (Fig. 3). Clusters contain functionally related genes based on their expression pattern. The middle circle represents a logarithm of fold change ( $\log F C)$ of differentially expressed genes assigned to the studied GO terms. The GO terms are shown as the outer ring. The genes whose expression is downregulated form clusters marked by blue part of the middle circle and analogously, red indicates upregulated genes. Clusters of the same color over the entire width of the outer circle represent genes that are unique for a specific GO term. Clusters of different colors on the cross section of outer circle show sets of genes which are likely to be functionally related. The dendrogram showed that many genes belong simultaneously to "cell motility" and "cell migration" or to "cell morphogenesis" and "cell morphogenesis involved in differentiation". The genes that are unique for a specific GO term belong mainly to "cell morphogenesis".
In the gene ontology database, single genes may belong to many ontological terms. For this reason, we used plots with visualization of $\operatorname{logFC}$ values and relationship between genes and selected GO BP terms (Fig. 4). The relationship was also presented as a heatmap (Fig. 5). The strongest upregulated genes from examined GO BP terms included, among others: ANXA3- annexin A3, KIAA1199, HTR2B- 5-hydroxytryptamine (serotonin) receptor 2B, G protein-coupled, VCAM1- vascular cell adhesion molecule 1 and DKK1-dickkopf WNT signaling pathway inhibitor 1 .

In the next part of analysis, we focused on the interaction between proteins encoded by DEGs belonging to studied GO BP terms. Firstly, we used STRING software for the interaction prediction. The number of genes used to create STRING interaction network was limited to 50 most changed DEGs for readability (Fig. 6).

Finally, we used ReactomeFIViz app for investigation of functional interactions between proteins en- 


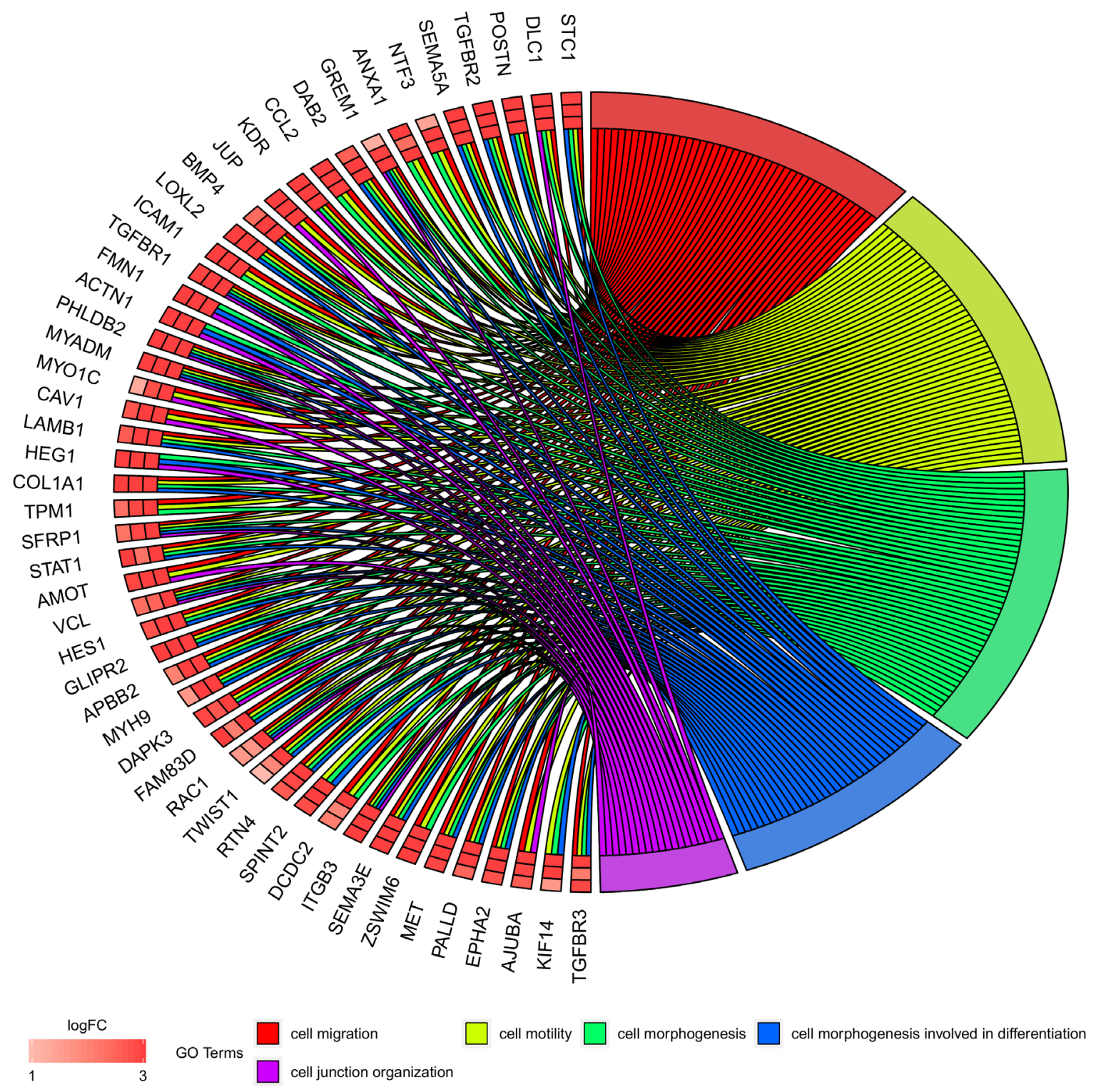

FIGURE 4 Analysis of enriched gene ontological groups involved in cellular morphogenesis, junction and migration. The network plot presenting the linkages of genes and GO BP terms

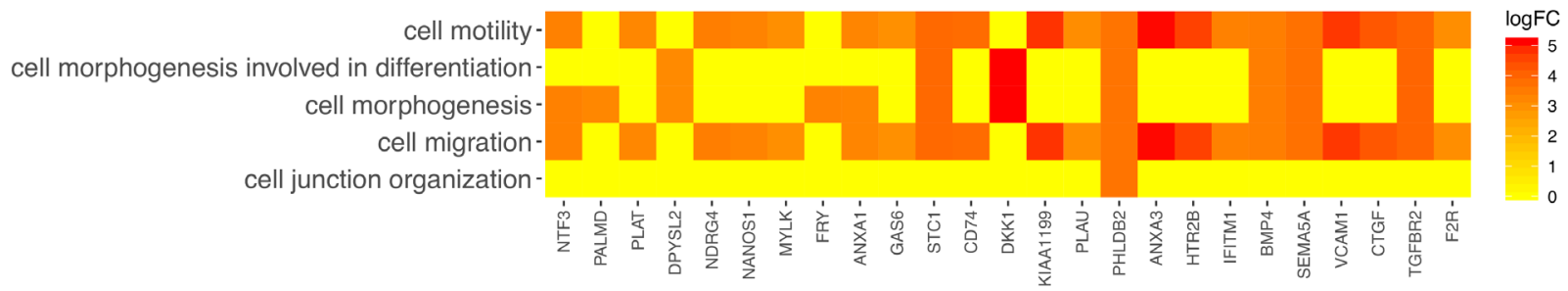

FIGURE 5 Heatmap presenting the relationship between genes and selected GO BP terms. The yellow color of tiles indicates the absence of $\log \mathrm{FC}$ values

coded by DEGs belonging to selected GO BP terms. Among the most significantly enriched functional interaction networks were FI networks for "Cell migration" and "Positive regulation of cell migration" (Figs 7 and 8).

\section{Discussion}

It is known that CCs are necessary in the process of acquiring developmental competence by the oocyte, including enabling the resumption of meiosis and the transition to the meiosis metaphase II 


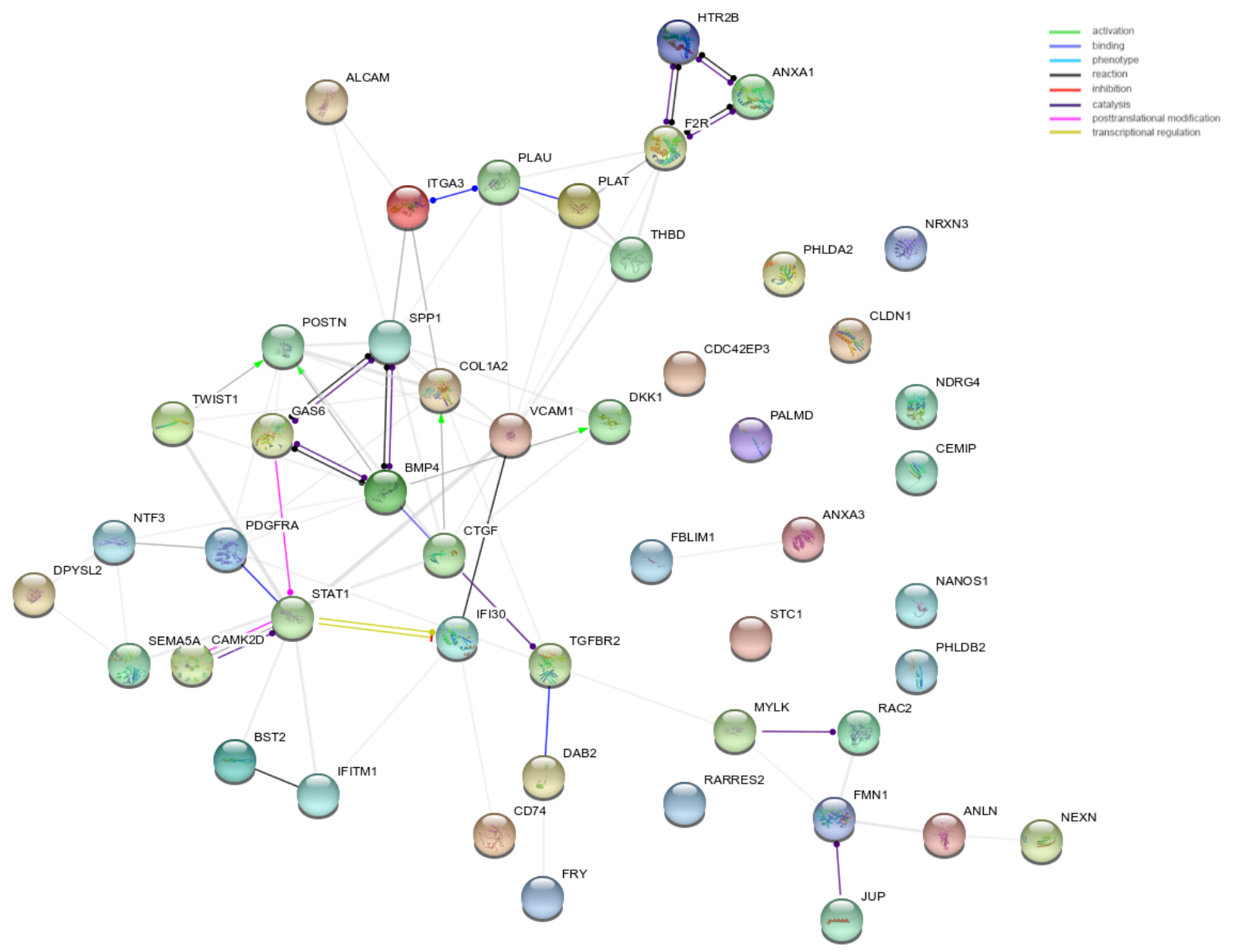

FIGURE 6 Interaction network of proteins encoded by 50 most changed DEGs belonging to "cell junction organization", "cell migration", "cell morphogenesis involved in differentiation", "cell morphogenesis" and "cell motility" GO BP terms. The network was generated by STRING software. Network nodes represent proteins. Empty nodes indicate proteins of unknown 3D structure

[25]. Thanks to the gap connections, it is possible to transport molecules between CCs cells and the oocyte [26]. Proper oocyte maturation without CCs is practically impossible, and the effectiveness of fertilization of such an oocyte and obtaining a correct blastocyst drastically decreases [27]. Furthermore, metabolomic studies of the spent culture medium obtained show that CCs are secreted into the external environment and allow oocyte maturation $[28,29]$. Due to the closeness and interaction of CCs and oocyte, they have become an interesting research model in embryology.

In the presented studies, during the transcriptome analysis of CCs cells maintained in long-term primary in vitro culture, groups of genes were selected, responsible primarily for processes associated with "cell junction organization", "cell morphogenesis involved in differentiation", cell morphogenesis", "cell motility", "cell migration". For the purposes of the presented research, these selected ontological groups can be conventionally divided into two group: 1) "cell motility", "cell migration" - here, genes are primarily responsible for the movement of cells from one place to another; 2) "cell junction organization", "cell morphogenesis involved in differentiation", "cell morphogenesis " are responsible for organizing the components of connections between two cells but also between the cell and the extracellular matrix. In addition, a second group of selected ontological groups describes the genes responsible for cell movement from one site to the destination directed by molecular information. Moreover, genes involved in shaping cells and changing their form, shape and size that occur when non-specialized cells acquire the specialized structural features of a cell population characteristic of an organ.

The presented research results indicate that the strongest upregulated genes from examined GO BP terms included, among others: DKK1, ANXA3, KIAA1199, VCAM1, HTR2B. Only 6 genes demonstrated downregulation relative to the reference value, which was the gene expression shown on day 1 of primary culture in vitro.

The factor conditioning correct embryo implantation is activation of canonical WNT signaling. The 


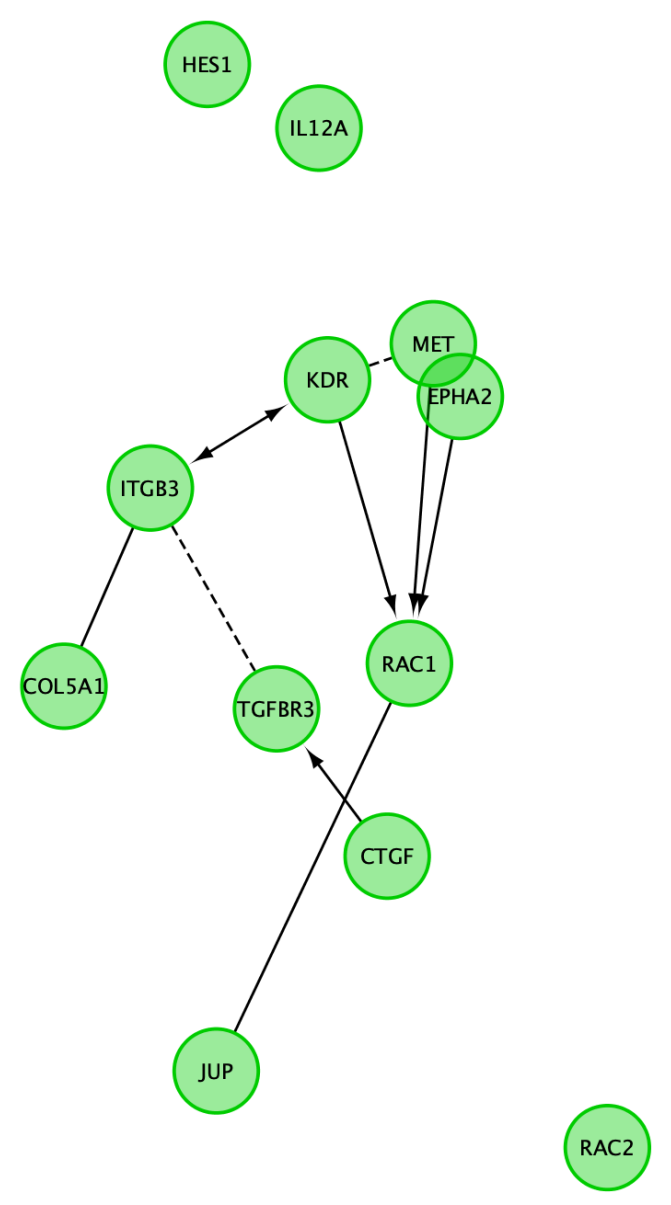

FIGURE 7 Reactome FI network for "Cell migration”. “--->” indicates activating/catalyzing, "-“ FIs extracted from complexes or inputs and "---" predicted FIs

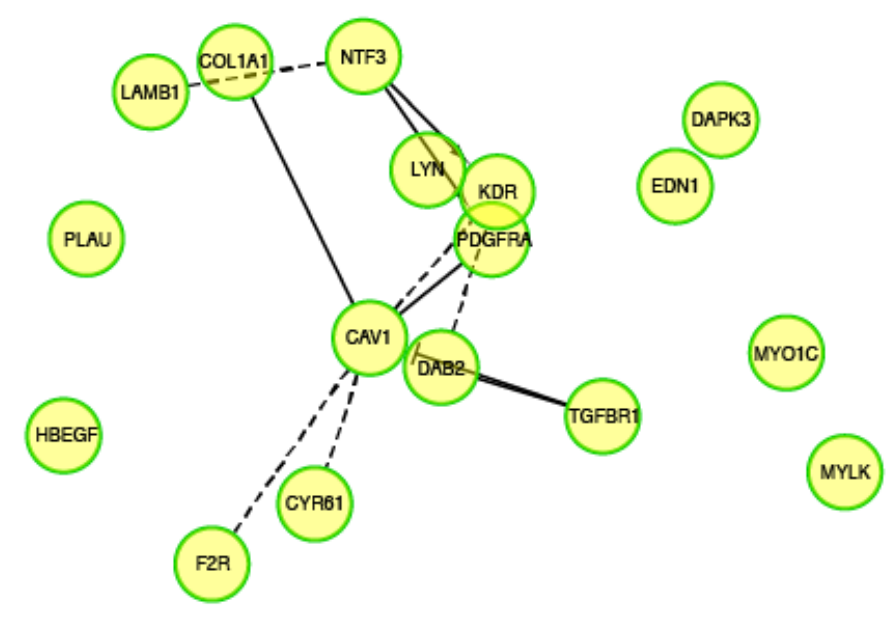

FIGURE 8 Reactome FI network for "Positive regulation of cell migration". “--->” indicates activating/catalyzing, "-“ FIs extracted from complexes or inputs and "---" predicted FIs

WNT signaling pathway is regulated by steroids $[30,31]$. WNT activation in the embryo may or may not affect the correct implantation of the embryo, but is responsible for regulating pluripotency [32]. $D K K 1$ is an antagonist of the WNT signaling pathway [33], as well as the protein produced by endometrial cells during the menstrual cycle, early pregnancy or estrus in other mammals [34,35]. It is believed, that the proper development of the embryo and the proper implantation depend on a number of regulatory factors secreted by the mother's reproductive system [36]. $D D K 1$ is also potentially involved in mother-embryo communication [37]. Studies on bovine embryos indicate that DKK1 facil- 
itates TE and hypoblast differentiation. DKK1 plays one of the key roles in the proper functioning of the reproductive system of most mammals, including humans [37-41]. In the light of our research and existing knowledge about the role of CCs in communication with the oocyte, high $D K K 1$ expression may also affect the quality of obtained blastocyst and its implantability [42]. Studies suggest that adding CCs cells to the embryo environment improves embryo quality and pregnancy rates.[43]. Perhaps the high expression of this gene in CCs cells may also affect the acquisition of oocyte developmental competences and then having sufficiently high pluripotent properties. Therefore, our research suggests that the presence of CCs cells in the oocyte environment during fertilization may result in improved in vitro fertilization efficiency.

The genes also responsible for the proper development of blastocyst include the ANXA3 gene. The protein encoded by this gene is responsible for binding and maintaining primarily cell membranes. ANX are proteins found in a variety of tissues, from the respiratory and urinary epithelium to the presence in peripheral nerves. Proteins from the anexin family due to their expression in individual tissues most likely take part in the processes of equalization of individual tissues, and are also partly responsible for their physiological properties [44]. The presented studies suggest an increase in ANXA3 gene expression in the following days of primary culture in vitro in the absence of oocyte. To date, the presence of the $A N X A 3$ gene has been reported in the morula and blastocyst stages during preimplantation development [45]. The ANXA3 protein is part of human neutrophils and promotes tight connections between membranes of individual neutrophils, which causes their aggregation [46-48].

As mentioned in the introduction, hyaluronan (HA), or hyaluronic acid, plays an important role in the reproductive system. It is produced primarily by the oocyte, embryo and other elements of the reproductive system, depending on the species of the mammal (fallopian tube, uterus, cervix) $[49,50]$. In addition, HA is produced by CCs and GCs cells [51,52]. The KIAA1199 (CEMIP; HYBID) gene showed a significant change in expression. The protein encoded by this gene plays a key role in depolymerization of HA molecules. Microarray analysis by Abe et al. it identified the expression of this gene in the cochlea, as well as in the inner ear [53]. Other studies claim that this gene is responsible for promoting the process of apoptosis, cancer progression. In addition, he is responsible for regulating cell proliferation, adhesion, motility and epithelial-mesenchymal transition cells of cancer. [54].

The gene closely related to cell adhesion and extracellular matrix modeling is VCAM1. It shows increased expression in GCs and CCs cells [55]. High expansion of the VCAM1 gene has also been demon- strated in mouse granular cells after dehydroepiandrosterone (DHEA) androgenization. The result of the increase in VCAM1 expression was an exacerbation of the symptoms of polycystic ovarian syndrome in mice (PCOS). It is suggested that VCAM1 expression knockout is one therapeutic option for PCOS [56]. Expression of the VCAM1 protein was not detected in mouse embryos prior to implantation. However, it is known that VCAM1 is present in oocytes and early human embryos $[57,58]$. The presented research results suggest that CCs cells in in-vitro culture medium show significant increase in expression in the following days of the in vitro primary culture. Perhaps the lack of interaction with the oocyte determines this growth.

Only 6 genes showed a decrease in expression relative to the control. In the presented article we focused on two genes the most downregulated ( $T G$ FBR3 and HMGB1).

In the presented studies, it seems surprising that the expression of TGFBR3 gene shows a decrease. This gene codes for the receptor protein for TGF-beta. The transforming growth factor family (TGF-beta) are multifunctional molecules involved in a number of processes primarily associated with tissue development, cell differentiation process, cell migration and adhesion, as well as the production of extracellular matrix. Receptor types I, II and III are involved in the action of TGF-beta. TGFBR3 is a TGF-beta binding glycoprotein that can have a membrane-bound form as well as a dissolved form [59]. This receptor may also exist as an inhibin co-receptor [60]. TGFBR3 expression in CCs cells during long-term culture decreases. This may be associated with a lack of communication with the oocyte and a change in the natural environment for CCs cells. The expression of TGFBR3 decreases during the development of breast cancer [61]. In studies on the effect of age on the quality of oocytes, TGFBR3 was found to be overexpressed in a group of women over 37 years of age [2]. It turns out that changing the environment to extracorporeal can have a great impact on obtaining oocyte developmental competences, as well as the development of the embryo and its proper implantation after transfer to the mother's uterus [62]. This factor can have a significant impact on the success and effectiveness of the in vitro fertilization procedure. The decrease in $T G$ FBR3 expression is associated with reduced oocyte developmental competence [63]. On the other hand, studies in mice prove that the Tgfbr3 knockout was associated with their high fertility and increased folliculogenesis [64].

HMGB1 is another gene that showed a decrease in expression. Melatonin has shown increased expression of this gene during oocyte maturation [65]. High expression of HMBG1 reduces blastocyst demand and thus increases the chances of embryo survival $[66,67]$. Moreover, studies show that there 
is a correlation with the amount of HMGB1 protein in follicular fluid (FF) and pregnancy and endometrial thickness. There are scientific reports confirming the fact that the protein encoded by the present gene can be an important indicator of the success of in vitro fertilization [68]. The protein encoded by the $H M G B 1$ gene is responsible for DNA binding and participates in transcription, DNA replication and repair. The decrease in expression of the presented gene may be the result of a change in the CCs cell culture environment. For transfer to in vitro conditions, we may suggest that these cells have lost their physiological properties [69].

\section{Conclusions}

The presented research results allowed to identify groups of genes responsible for processes related to "cell junction organization", "cell morphogenesis involved in differentiation", "cell morphogenesis", "cell motility", and "cell migration", as well as to define interactions between individual genes. The results suggest that the most upregulated genes are primarily responsible for processes related to communication with the oocyte as well as the proper development of the embryo and its implantation. The obtained results indicate that in in vitro cultured CCs do not lose their properties or, on the contrary, their gene expression decreases due to the loss of contact with the oocyte.

\section{Acknowledgements}

This research was funded by National Science Centre, UMO-2018/31/B/NZ5/02475.

\section{Corresponding author}

Bartosz Kempisty Ph.D., Department of Histology and Embryology, Department of Anatomy, Poznań University of Medical Sciences, 6 Święcickiego St., 60-781 Poznań, Poland Tel./Fax: +48 618546567 / +48 61 8546568, e-mail: bkempisty@ump.edu.pl.

\section{Conflict of interest statement}

The authors declare they have no conflict of interest

\section{References}

1. Russell DL, Robker RL. Molecular mechanisms of ovulation: co-ordination through the cumulus complex. Hum Reprod Update. n.d.13(3):289312; DOI:10.1093/humupd/dml062.

2. Al-Edani T, Assou S, Ferrières A, Bringer Deutsch $\mathrm{S}$, Gala $\mathrm{A}$, Lecellier $\mathrm{C}-\mathrm{H}$, Aït-Ahmed O, Hamamah S. Female Aging Alters Expression of Human Cumulus Cells Genes that Are Essential for Oocyte Quality. Biomed Res Int. 2014;2014; DOI:10.1155/2014/964614.

3. Eppig JJ. Oocyte control of ovarian follicular development and function in mammals. Reproduction. 2001;122(6):829-38.

4. Yeo CX, Gilchrist RB, Lane M. Disruption of Bidirectional Oocyte-Cumulus Paracrine Signaling During In Vitro Maturation Reduces Subsequent Mouse Oocyte Developmental Competence1. Biol Reprod. 2009;80(5):1072-80; DOI:10.1095/biolreprod.108.073908.

5. Parrish EM, Siletz A, Xu M, Woodruff TK, Shea LD. Gene expression in mouse ovarian follicle development in vivo versus an ex vivo alginate culture system. Reproduction. 2011;142(2):309-18; DOI:10.1530/ REP-10-0481.

6. Dzafic E, Stimpfel M, Novakovic S, Cerkovnik P, Virant-Klun I. Expression of mesenchymal stem cells-related genes and plasticity of aspirated follicular cells obtained from infertile women. Biomed Res Int. 2014;2014:508216; DOI:10.1155/2014/508216.
7. Elvin JA, Clark AT, Wang P, Wolfman NM, Matzuk MM. Paracrine actions of growth differentiation factor-9 in the mammalian ovary. Mol Endocrinol. 1999;13(6):1035-48; DOI:10.1210/mend.13.6.0310.

8. Tanghe S, Van Soom A, Nauwynck H, Coryn M, de Kruif A. Minireview: Functions of the cumulus oophorus during oocyte maturation ovulation, and fertilization. Mol Reprod Dev. 2002;61(3):414-24; DOI:10.1002/mrd.10102.

9. Chung M-K, Chiu PCN, Lee C-L, Pang RTK, Ng EHY, Lee K-F, Koistinen R, Koistinen H, Seppala M, Yeung WSB. Cumulus-associated alpha2-macroglobulin derivative retains proconceptive glycodelin-C in the human cumulus matrix. Hum Reprod. 2009;24(11):2856-67; D0I:10.1093/ humrep/dep265.

10. Pincus G, Enzmann E V. The comparative behavior of mammalian eggs in vivo and in vitro. J Exp Med. 1935;62(5):665-76; DOI:10.1084/ jem.62.5.665

11. Kölle S, Dubielzig S, Reese S, Wehrend A, König P, Kummer W. Ciliary Transport, Gamete Interaction, and Effects of the Early Embryo in the Oviduct: Ex Vivo Analyses Using a New Digital Videomicroscopic System in the Cow1. Biol Reprod. 2009;81(2):267-74; DOI:10.1095/ biolreprod.108.073874.

12. Host E, Gabrielsen A, Lindenberg S, Smidt-Jensen S. Apoptosis in human cumulus cells in relation to zona pellucida thickness variation, maturation stage, and cleavage of the corresponding oocyte after intracytoplasmic sperm injection. Fertil Steril. 2002;77(3):511-5; DOI:10.1016/ S0015-0282(01)03006-0.

13. Ullah I, Subbarao RB, Rho GJ. Human mesenchymal stem cells - current trends and future prospective. Biosci Rep. 2015;35(2); DOI:10.1042/ BSR20150025.

14. Russell DL, Gilchrist RB, Brown HM, Thompson JG. Bidirectional communication between cumulus cells and the oocyte: Old hands and new players? Theriogenology. 2016;86(1):62-8; DOI:10.1016/j. theriogenology.2016.04.019.

15. Matos L, Stevenson D, Gomes F, Silva-Carvalho JL, Almeida H. Superoxide dismutase expression in human cumulus oophorus cells. Mol Hum Reprod. 2009;15(7):411-9; DOI:10.1093/molehr/gap034.

16. Klein NA, Battaglia DE, Fujimoto VY, Davis GS, Bremner WJ, Soules MR. Reproductive aging: accelerated ovarian follicular development associated with a monotropic follicle-stimulating hormone rise in normal older women. J Clin Endocrinol Metab. 1996;81(3):1038-45; DOI:10.1210/ jcem.81.3.8772573.

17. Seino T, Saito H, Kaneko T, Takahashi T, Kawachiya S, Kurachi H. Eighthydroxy-2'-deoxyguanosine in granulosa cells is correlated with the quality of oocytes and embryos in an in vitro fertilization-embryo transfer program. Fertil Steril. 2002;77(6):1184-90; DOI:10.1016/ s0015-0282(02)03103-5.

18. Freimann S, Ben-Ami I, Dantes A, Ron-El R, Amsterdam A. EGF-like factor epiregulin and amphiregulin expression is regulated by gonadotropins/ cAMP in human ovarian follicular cells. Biochem Biophys Res Commun. 2004;324(2):829-34; DOI:10.1016/j.bbrc.2004.09.129.

19. Mohammed EE, Yilmaz S, Akcin OA, Nalbantoglu B, Ficicioglu C, Sahin $\mathrm{F}$, et al. Cumulus cells are potential candidates for cell therapy. In Vivo (Brooklyn). 2019;33(6):1921-7; DOI:10.21873/invivo.11686.

20. Russell DL, Gilchrist RB, Brown HM, Thompson JG. Bidirectional communication between cumulus cells and the oocyte: Old hands and new players? Theriogenology. 2016;86(1):62-8; DOI:10.1016/j. theriogenology.2016.04.019.

21. Ben-Meir A, Kim K, McQuaid R, Esfandiari N, Bentov Y, Casper R, Jurisicova A. Co-Enzyme Q10 Supplementation Rescues Cumulus Cells Dysfunction in a Maternal Aging Model. Antioxidants. 2019;8(3):58; DOI:10.3390/antiox8030058.

22. Ciesiółka S, Budna J, Jopek K, Bryja A, Kranc W, Chachuła A, Borys S, Dyszkiewicz Konwińska M, Ziółkowska A, Antosik P, Bukowska D, Brüssow KP, Bruska M, Nowicki M, Zabel M, Kempisty B. Influence of Estradiol-17beta on Progesterone and Estrogen Receptor mRNA Expression in Porcine Follicular Granulosa Cells during Short-Term, In Vitro Real-Time Cell Proliferation. Biomed Res Int. 2016;2016:1-8, DOI:10.1155/2016/8431018.

23. Chomczynski P, Sacchi N. Single-step method of RNA isolation by acid guanidinium thiocyanate-phenol-chloroform extraction. Anal Biochem. 1987;162(1):156-9; DOI:10.1016/0003-2697(87)90021-2.

24. Walter W, Sánchez-Cabo F, Ricote M. GOplot: an R package for visually combining expression data with functional analysis: Fig. 1. Bioinformatics. 2015;31(17):2912-4; DOI:10.1093/bioinformatics/btv300.

25. Sun M-H, Zheng J, Xie F-Y, Shen W, Yin S, Ma J-Y. Cumulus Cells Block Oocyte Meiotic Resumption via Gap Junctions in Cumulus Oocyte Complexes Subjected to DNA Double-Strand Breaks. PLoS One. 2015;10(11):e0143223; DOI:10.1371/journal.pone.0143223. 
26. Kempisty B, Ziółkowska A, Piotrowska H, Zawierucha P, Antosik P, Bukowska D, Ciesiółka S, Jaśkowski JM, Brüssow KP, Nowicki M, Zabe M. Real-time proliferation of porcine cumulus cells is related to the protein levels and cellular distribution of $\mathrm{Cdk} 4$ and $\mathrm{Cx} 43$. Theriogenology. 2013;80(4):411-20; DOI:10.1016/j.theriogenology.2013.05.016.

27. De los Santos MJ, Gámiz P, de los Santos JM, Romero JL, Prados N, Alonso C, Remohí J, Dominguez F. The Metabolomic Profile of Spent Culture Media from Day-3 Human Embryos Cultured under Low Oxygen Tension. PLoS One. 2015;10(11):e0142724; DOI:10.1371/journal. pone.0142724.

28. Uhde K, Van Tol HTA, Stout TAE, Roelen BAJ. Metabolomic profiles of bovine cumulus cells and cumulus-oocyte-complex-conditioned medium during maturation in vitro. Sci Rep. 2018;8(1):1-14; DOI:10.1038/ s41598-018-27829-9.

29. Zhu J, Zhang J, Li H, Wang TY, Zhang CX, Luo MJ, Tan JH. Cumulus cells accelerate oocyte aging by releasing soluble Fas Ligand in mice. Sci Rep. 2015;5(1):1-8; DOI:10.1038/srep08683.

30. Franco HL, Dai D, Lee KY, Rubel CA, Roop D, Boerboom D, Jeong J-W, Lydon JP, Bagchi IC, Bagchi MK, DeMayo FJ. WNT4 is a key regulator of normal postnatal uterine development and progesterone signaling during embryo implantation and decidualization in the mouse. FASEB J. 2011;25(4):1176-87; DOI:10.1096/fj.10-175349.

31. Satterfield MC, Song G, Hayashi K, Bazer FW, Spencer TE. Progesterone regulation of the endometrial WNT system in the ovine uterus. Reprod Fertil Dev. 2008;20(8):935-46; DOI:10.1071/rd08069.

32. Sato N, Meijer L, Skaltsounis L, Greengard P, Brivanlou AH. Maintenance of pluripotency in human and mouse embryonic stem cells through activation of Wnt signaling by a pharmacological GSK-3-specific inhibitor. Nat Med. 2004;10(1):55-63; DOI:10.1038/nm979.

33. Hernandez Gifford JA. The role of WNT signaling in adult ovarian folliculogenesis. Reproduction. 2015;150(4):R137-48; DOI:10.1530/ REP-14-0685.

34. Tulac S, Nayak NR, Kao LC, Van Waes M, Huang J, Lobo S, Germeyer A, Lessey BA, Taylor R.N, Suchanek E, Giudice LC. Identification, characterization, and regulation of the canonical Wnt signaling pathway in human endometrium. J Clin Endocrinol Metab. 2003;88(8):3860-6; DOI:10.1210/jc.2003-030494.

35. Minten MA, Bilby TR, Bruno RGS, Allen CC, Madsen CA, Wang Z, Sawyer, Jason E, Tibary A, Neibergs HL, Geary TW, Bauersachs S, Spence TE. Effects of Fertility on Gene Expression and Function of the Bovine Endometrium. PLoS One. 2013;8(8):e69444; DOI:10.1371/journal. pone.0069444

36. Gad A, Hoelker M, Besenfelder U, Havlicek V, Cinar U, Rings F, Held E, Dufort I, Sirard M-A, Schellander K, Tesfaye D. Molecular Mechanisms and Pathways Involved in Bovine Embryonic Genome Activation and Their Regulation by Alternative In Vivo and In Vitro Culture Conditions1. Biol Reprod. 2012;87(4); DOI:10.1095/biolreprod.112.099697.

37. Denicol AC, Block J, Kelley DE, Pohler KG, Dobbs KB, Mortensen CJ, Ortega MS, Hansen PJ. The WNT signaling antagonist Dickkopf-1 directs lineage commitment and promotes survival of the preimplantation embryo. FASEB J. 2014;28(9):3975-86; DOI:10.1096/fj.14-253112.

38. Macdonald LJ, Sales KJ, Grant V, Brown P, Jabbour HN, Catalano RD. Prokineticin 1 induces Dickkopf 1 expression and regulates cell proliferation and decidualization in the human endometrium. Mol Hum Reprod. 2011;17(10):626-36; DOI:10.1093/molehr/gar031.

39. Kelly KF, Ng DY, Jayakumaran G, Wood GA, Koide H, Doble BW. $\beta$-catenin enhances Oct-4 activity and reinforces pluripotency through a TCF-independent mechanism. Cell Stem Cell. 2011;8(2):214-27; DOI:10.1016/j. stem.2010.12.010.

40. Kao LC, Tulac S, Lobo S, Imani B, Yang JP, Germeyer A, Osteen K, Taylor RN, Lessey BA, Giudice LC. Global gene profiling in human endometrium during the window of implantation. Endocrinology. 2002;143(6):2119 38; DOI:10.1210/endo.143.6.8885.

41. Zhang RJ, Zou LB, Zhang D, Tan YJ, Wang TT, Liu AX, Qu F, Meng Y, Ding GL, Lu YC, Lv PP Sheng JZ, Huang HF. Functional expression of large-conductance calcium-activated potassium channels in human endometrium: A novel mechanism involved in endometrial receptivity and embryo implantation. J Clin Endocrinol Metab. 2012;97(2):543-53 DOI:10.1210/jc.2011-2108.

42. Spate LD, Brown AN, Redel BK, Whitworth KM, Murphy CN, Prather RS. Dickkopf-Related Protein 1 Inhibits the WNT Signaling Pathway and Improves Pig Oocyte Maturation. PLoS One. 2014;9(4):e95114; DOI:10.1371/journal.pone.0095114.

43. Aktan TM, Görkemli H, Gezginç K, Saylan A, Duman S, Yilmaz FY. Improvement in embryo quality and pregnancy rates by using autologous cumulus body during icsi cycles. J Turkish Ger Gynecol Assoc. 2011;12(3):162-7; DOI:10.5152/jtgga.2011.38.
44. Dreier R, Schmid KW, Gerke V, Riehemann K. Differential expression of annexins I, II and IV in human tissues: An immunohistochemical study. Histochem Cell Biol. 1998;110(2):137-48; DOI:10.1007/ s004180050275.

45. Hamatani T, Carter MG, Sharov AA, Ko MSH. Dynamics of global gene expression changes during mouse preimplantation development. Dev Cell. 2004;6(1):117-31; DOI:10.1016/S1534-5807(03)00373-3.

46. Sopkova J, Raguenes-Nicol C, Vincent M, Chevalier A, Lewit-Bentley A Russo-Marie F, Gallay J. Ca2+ and membrane binding to annexin 3 modulate the structure and dynamics of its $\mathrm{N}$ terminus and domain III. Protein Sci. 2009;11(7):1613-25; DOI:10.1110/ps.4230102.

47. Le Cabec V, Maridonneau-Parini I. Annexin 3 is associated with cytoplasmic granules in neutrophils and monocytes and translocates to the plasma membrane in activated cells. Biochem J. 1994;303(2):481-7; DOI:10.1042/bj3030481

48. Le Cabec V, Russo-Marie F, Maridonneau-Parini I. Differential expression of two forms of annexin 3 in human neutrophils and monocytes and along their differentiation. Biochem Biophys Res Commun. 1992;189(3):1471-6; DOI:10.1016/0006-291x(92)90240-l.

49. Afify A, McNiel MA, Braggin J, Bailey H, Paulino AF. Expression of CD44s, CD44v6, and hyaluronan across the spectrum of normal-hyperplasia-carcinoma in breast. Appl Immunohistochem Mol Morphol. 2008;16(2):121-7; DOI:10.1097/PAI.0b013e318047df6d.

50. Akgul Y, Holt R, Mummert M, Word A, Mahendroo M. Dynamic Changes in Cervical Glycosaminoglycan Composition during Normal Pregnancy and Preterm Birth. Endocrinology. 2012;153(7):3493-503; DOI:10.1210/en.2011-1950.

51. Kimura M, Kim E, Kang W, Yamashita M, Saigo M, Yamazaki T, Nakanishi T, Kashiwabara S-I, Baba T. Functional Roles of Mouse Sperm Hyaluronidases, HYAL5 and SPAM1, in Fertilization1. Biol Reprod. 2009;81(5):939-47; DOI:10.1095/biolreprod.109.078816.

52. Fouladi-Nashta AA, Raheem KA, Marei WF, Ghafari F, Hartshorne GM. Regulation and roles of the hyaluronan system in mammalian reproduction. Reproduction. 2017;153(2):R43-58; DOI:10.1530/REP-16-0240.

53. Abe S, Katagiri T, Saito-Hisaminato A, Usami SI, Inoue Y, Tsunoda T, Nakamura Y. Identification of CRYM as a candidate responsible for nonsyndromic deafness, through cDNA microarray analysis of human cochlear and vestibular tissues. Am J Hum Genet. 2003;72(1):73-82; DOI:10.1086/345398.

54. Zhang Y, Jia S, Jiang WG. KIAA1199 and its biological role in human cancer and cancer cells (Review). Oncol Rep. 2014;31(4):1503-8; DOI:10.3892/or.2014.3038.

55. Borgbo T, Povlsen BB, Andersen CY, Borup R, Humaidan P, Grøndah ML. Comparison of gene expression profiles in granulosa and cumulus cells after ovulation induction with either human chorionic gonadotropin or a gonadotropin-releasing hormone agonist trigger. Fertil Steril. 2013;100(4):994-1001.e2; D0I:10.1016/j.fertnstert.2013.05.038.

56. Solano ME, Sander VA, Ho H, Motta AB, Arck PC. Systemic inflammation, cellular influx and up-regulation of ovarian VCAM-1 expression in a mouse model of polycystic ovary syndrome (PCOS). J Reprod Immunol. 2011;92(1-2):33-44; DOI:10.1016/j.jri.2011.09.003.

57. Campbell S, Swann HR, Seif MW, Kimber SJ, Aplin JD. Integrins and adhesion mlecules: Cell adhesion molecules on the oocyte and preimplantation human embryo. Hum Reprod. 1995;10(6):1571-8; DOI:10.1093/ HUMREP/10.6.1571.

58. Campbell S, Swann HR, Seif MW, Kimber SJ, Aplin JD. Cell adhesion molecules on the oocyte and preimplantation human embryo. Hum Reprod. 1995;10(6):1571-8; DOI:10.1093/humrep/10.6.1571.

59. Brown CB, Boyer AS, Runyan RB, Barnett J V. Requirement of type III TGF- $\beta$ receptor for endocardial cell transformation in the heart. Science (80- ). 1999;283(5410):2080-2; DOI:10.1126/science.283.5410.2080.

60. Lewis KA, Gray PC, Blount AL, MacConell LA, Wiater E, Bitezikjian LM, Vate W. Betaglycan binds inhibin and can mediate functional antagonism of activin signalling. Nature. 2000;404(6776):411-4; DOI:10.1038/35006129.

61. Dong M, How T, Kirkbride KC, Gordon KJ, Lee JD, Hempel N, Kelly P, Moeller BJ, Marks JR, Blobe GC. The type III TGF- $\beta$ receptor suppresses breast cancer progression. J Clin Invest. 2007;117(1):206-17; DOI:10.1172/JCI29293.

62. Sarraj M, Chua HK, Umbers A, Loveland K, Findlay J, Stenvers KL. Differential expression of TGFBR3 (betaglycan) in mouse ovary and testis during gonadogenesis. Growth Factors. 2007;25(5):334-45; DOI:10.1080/08977190701833619.

63. O'Shea LC, Mehta J, Lonergan P, Hensey C, Fair T. Developmental competence in oocytes and cumulus cells: candidate genes and networks. Syst Biol Reprod Med. 2012;58(2):88-101; DOI:10.3109/19396368.20 12.656217 . 
64. Li Y, Fortin J, Ongaro L, Zhou X, Boehm U, Schneyer A, Bernard DJ, Lin HY. Betaglycan (TGFBR3) Functions as an Inhibin A, but Not Inhibin B, Coreceptor in Pituitary Gonadotrope Cells in Mice. Endocrinology. 2018;159(12):4077-91; DOI:10.1210/en.2018-00770.

65. Salimi M, Salehi M, Masteri Farahani R, Dehghani M, Abadi M, Novin MG, Nourozian M, Hosseini A. The Effect of Melatonin on Maturation, Glutathione Level and Expression of H MGB1 Gene in Brilliant Cresyl Blue (BCB) Stained Immature Oocyte. Cell J. 2014;15(4):294-301.

66. Tang D, Shi Y, Kang R, Li T, Xiao W, Wang H, Xiao X. Hydrogen peroxide stimulates macrophages and monocytes to actively release HMGB1. Leukoc Biol. 2007;81(3):741-7; DOI:10.1189/jlb.0806540.

67. Cui X-S, Shen X-H, Kim N-H. High mobility group box 1 (HMGB1) is implicated in preimplantation embryo development in the mouse. Mol Reprod Dev. 2008;75(8):1290-9; DOI:10.1002/mrd.20694.

68. Li SJ, Yin T, Li W, Yang J, Xu WM, Zhou D. Association between follicular fluid levels of HMGB1 protein and outcomes in patients undergoing in vitro fertilization/intracytoplasmic sperm

69. Lotze MT, Tracey KJ. High-mobility group box 1 protein (HMGB1): Nuclear weapon in the immune arsenal. Nat Rev Immunol. 2005;5(4):33142; DOI:10.1038/nri1594. 